\title{
Improving car environmental and operational characteristics using a multifunctional fuel additive
}

\author{
E. Magaril \\ Department of Economics and Organization of Chemical Industries, \\ Ural Federal University, Russia
}

\begin{abstract}
Vehicle modernization has been developed towards the growing necessities of speed, power, efficiency, ergonomics, and design etc. The requirements, nowadays of environmental safety and operational efficiency of vehicles are being brought to the forefront. The aim of this work is to increase efficiency and reduce the harmful environmental impact of automobile transport by improving the quality of fuels during its operation. The improvement of the quality of fuels by means of highly-effective additives is the most rapidly implemented and lowcost method. According to the settled requirements of the properties of additives and the analysis of the catalytic and physicochemical properties of the substances, the universal content of the additive to gasoline and diesel fuel was found and the technology of its production was proposed. In addition, the additive was thoroughly tested in the laboratory, test bench, traffic operation and experimental-industrial checkout. It was found that the application of the additive in minor quantities significantly improves operational and environmental properties of fuels and engine characteristics.

Keywords: multifunctional additive, carbonization suppression, fuel consumption, environmental and operational characteristics of vehicles.
\end{abstract}

\section{Introduction}

Transport with its consumption of engine fuel of about 2 billion tons per year is one of the most important factors which determine the state of the world economy and, as a consequence, geopolitics. The most important problems facing humanity in this connection are the problems of environmental 
deterioration and exhaustion of the petroleum and natural gas resources. Environmental safety and efficiency of vehicle operation are influenced by many factors such as the size of the vehicle fleet, the quality of car maintenance, the fuel's characteristics, the road network, traffic management, environmental conditions and regulations. The fastest and least expensive way to improve the environmental and operational characteristics of vehicles of the current state of the vehicle fleet and the quality of engine fuels is the introduction of highly effective fuel additives affecting the individual fuel characteristics or its quality in common (multifunctional additives). It should be noted that the current state of the petroleum-refining methods cannot provide the required level of such fuel characteristics as its cleaning and lubricating properties, which can be easily improved by using the appropriate additives. At the present time there are about 2.500 brands of fuel additives on the world market and only in the United States, their consumption exceeds considerably 100 tons a year. In Russia, the improvement of the quality of engine fuels which influences the operational and environmental performance of vehicles has a special significance under the conditions of the rapid growth of the number of vehicles simultaneously with the steady quality of fuels or even its worsening. The decision taken in this regard should be based on scientifically sound conclusions about the influence of physicochemical properties of fuels and fuel additives on the operating and environmental characteristics of vehicles.

\section{The requirements for the multifunctional fuel additive}

Based on the theoretical investigations of the influence of fuel quality on the operating and environmental characteristics of vehicles, [1], the data of the catalytic and physicochemical properties of substances we have formulated the requirements for the properties of additives which can improve vehicles' environmental and operational characteristics.

\subsection{The requirements for carbonization suppression in engines}

The maximum temperature reached during the combustion of fuel-air mixture in an engine, is determined by other equal conditions by heat transfer to the cylinder walls, which is mainly determined by their temperature, $[1,2]$. Due to the high thermal conductivity of metal, the wall temperature does not differ greatly from the cooling water temperature. However, the carbon deposit formation during the operation reduces significantly the heat transfer through the walls, because it's coefficient of thermal conductivity in $1-2 \times 10^{3}$ times and heat capacity about 3 times lower than that of metal. Carbon deposit layer even of low thickness causes an increase of the temperature of engine's walls because of its insulating properties. Our calculations showed that after the carbon deposition an increase of the wall's temperature by 200 degrees and more takes place depending on the thickness of the layer, the fraction of carbon in the amorphous state in it, as well as a coolant temperature. It reduces of the heat radiation from the volume of the chamber through the walls by $5-10 \%$ or more and leads to the 
increase of peak temperature of the combustion chamber. When the process of carbonization in the combustion chamber reaches certain equilibrium in its thickness, to provide operation of a gasoline engine without detonation in practice the octane number of gasoline usually should be increased by 10 points. In addition, carbon deposit, as a reaction-active substance, inclines to selfignition at $330-360^{\circ}$. Scorching during the burning of fuel mixture and emission of the products of combustion, carbon deposit, due to its low thermal conductivity, keeps the heat and propensity to interact with oxygen in the inlet fuel with the formation of "hot spots" causing the initiation of combustion before sparking. The "surface ignition" appears. Premature combustion in the compression stroke, in turn, leads to the significant increase in energy consumption for the compression, the increase of fuel specific consumption and the decrease of engine power. The rate of heating of the working mixture in the compression stroke grows as a result of the surface ignition that gives additional opportunity for detonation in gasoline engines.

In addition, the carbonization on the working surfaces of the engine increases significantly the friction that leads to the growth of the fuel specific consumption and the reduction of engine power.

Elimination of carbonization, therefore, because of mitigation of the temperature regime in the engine, will reduce the requirements for the octane number of gasoline used up to 10 points, and provide the increase of the power of gasoline and diesel engines and the reduction of fuel specific consumption. Furthermore, the removal of carbon deposit in gasoline engines is accompanied by the almost complete elimination of emission of polycyclic aromatic hydrocarbons, precursors of carbon deposit, including benzo(a)pyrene, one of the strongest carcinogens. It should be also noted that the reduction of the fuel specific consumption will lead to a corresponding reduction of emission and the amount of "greenhouse gases" $\left(\mathrm{CO}_{2}, \mathrm{CH}_{4}\right.$, etc. $)$.

The calculated dependences of equilibrium constants of the reactions determining the formation of oxides of nitrogen and carbon (NO and $\mathrm{CO}$ ) in the engine on temperature, $[1,2]$ show that the decrease of peak temperature in the combustion chamber due to enhancement of heat transfer through the walls with carbon deposit elimination in its turn will lead to a considerable decrease of nitrogen and carbon's oxides emission.

The amount of carbon deposit on the wall's surface is determined by ratio of the condensation rate of aromatic and unsaturated hydrocarbon in the wall boundary layer and the rate of oxidation and gasification of products of condensation (and their precursors) by oxygen, water and carbon dioxide. Therefore, the additive should catalyze effectively the reactions of oxidation and gasification.

\subsection{The requirements for the decrease of unburned combustibles' emission}

The additive should decrease the amount of unburned combustibles in outlet gases - hydrocarbons and their oxy derivatives. As such substances are generated mainly in the wall boundary layer in the low temperature area, the 
additive should catalyze full oxidation and gasification (under the lack of oxygen) of hydrocarbons and their oxy derivatives.

\subsection{The requirements for the decrease of nitrogen and carbon's oxides emission}

The additive should provide decomposition and (or) reduction of nitrogen oxide and oxidation of carbon monoxide, in other words, it should catalyze the reactions:

$$
\begin{gathered}
2 \mathrm{NO} \rightarrow \mathrm{N}_{2}+\mathrm{O}_{2} \\
2 \mathrm{NO}+2 \mathrm{CO} \rightarrow \mathrm{N}_{2}+2 \mathrm{CO}_{2} \\
2 \mathrm{CO}+\mathrm{O}_{2} \rightarrow 2 \mathrm{CO}_{2}
\end{gathered}
$$

\subsection{The requirements for the decrease of soot emission}

The additive should suppress soot production. In principle, it is possible by means of facilitation of nucleation of soot production that leads to increasing of its dispersion. The rate of soot burning in a flame front is proportional to the specific surface of soot particles, therefore increasing of its dispersion leads to increasing of the degree of its burning. The catalysis of carbon burning gives another possibility to the growth of the degree of soot burning in the flame front.

\subsection{The requirements for the enhancement of the detergent properties of fuels}

To ensure the cleanness of the fuel system of vehicles, as well as undisturbed operation of engines with fuel injection the high detergent properties of fuels are required, which cannot be reached by methods of oil refining but can be achieved easily by application of fuel additives. The additive should effectively improve the detergent properties of fuel. It is possible if the additive has a high surface activity, providing the tar solubilization or formation of the durable adsorption layers on the metal surface, preventing the deposition of tar.

\subsection{The requirements for the increase of the cetane number of diesel fuel}

The value of the cetane number of diesel fuel affects a number of operational parameters of diesel engines: the time of cold start, the rate of use of fuel, the efficiency of the engine. The additive should enhance the cetane number of diesel fuel, i.e. it should be a catalyst for ignition.

\subsection{The requirement for the improvement of the inlet mixture formation in the engine}

Our studies showed that the spraying of fuel of given quality can be improved by the introduction of surfactants into the fuel, which reduce surface tension of the fuel-air interface. Therefore the additive should possess the high surface activity. 


\subsection{The requirement for the improvement of the low temperature properties of diesel fuel}

The additive should decrease the limiting temperature of filterability of diesel fuel, which defines the possibility of its utilization under the low temperatures which is a great importance in Russia.

\subsection{The requirement for the increase of the wear-resistant properties of fuel}

The high pressure fuel pump of diesel engines undergoes wear of the pump internal elements. The anti wear properties of diesel fuel with reduced sulfur content in it decrease sharply, and can be improved only by introduction of additives which are the surface-active substances. Therefore, the additive should possess the surface activity and improve lubricating properties of diesel fuel.

\subsection{The requirement for the solubility in the fuel}

The additive should form a true solution in the fuel under all conditions during its application. Otherwise, it will negatively affect the engine performance.

\subsection{The requirement for the unavailability of additional pollutants}

The additive should not be the source of making new toxic substances which are not produced in fuel without additives.

\subsection{The requirement for the accessibility and low cost of raw materials}

The additive should be synthesized from available materials and it should not affect significantly the cost of fuel.

Based on the stated requirements and screening of the data on the catalytic properties of substances, the composition of oil-soluble multifunctional additive and technology of its production was developed, and its optimal concentration in fuel is $9.25 \mathrm{ppm}$ for gasoline and $27.75 \mathrm{ppm}$ for diesel fuel was found.

\section{The testing results of the additive application}

The additive was thoroughly tested in the laboratory, test bench, traffic operation and experimental-industrial checkout. The studies of influence of multifunctional additive on the process of an engine's carbonization showed that the additive concentration of $9.25 \cdot \mathrm{ppm}$ in gasoline and $27.75 \mathrm{ppm}$ in diesel fuel was enough to eliminate carbon deposits almost completely. In addition, a positive effect of the additive on the mixture formation in engines, the decrease of the probability of dripping on the walls with subsequent formation of carbon deposit, was found. The testing of the influence of the additive on the fuel consumption on a diesel engine of locomotive 2TE116 № 42 showed that the reduction of the fuel 
consumption after 9 hours of operation on fuel with the additive was $6.9 \%$. The combustion chamber of one of the cylinders was unsealed before and after the testing run on fuel with the additive. It was found that amount of carbon deposit in the combustion chamber on the valves and piston crown decreased sharply (fig. 1).

a)
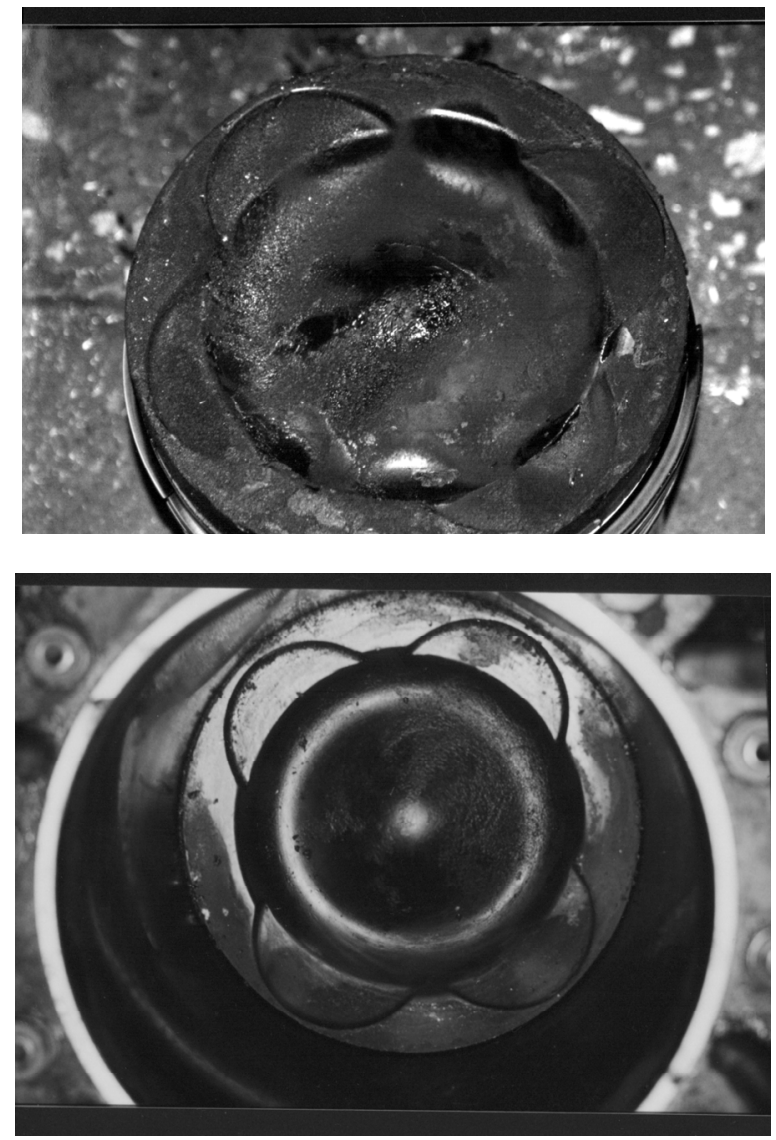

b)

Figure 1: The outward of piston's crown of diesel engine of locomotive 2ТЭ116 №42: a) Before the additive application; b) After 9 hours of testing run on fuel with the additive.

The additive with the concentration of $27.75 \mathrm{ppm}$ under on-peak load during the test of the diesel bench engine reduced the soot content by $50 \%$. $\mathrm{CO}, \mathrm{CH}$ and $\mathrm{NO}_{2}$ were decreased, respectively, by $14.6,37.2$ and $20.6 \%$. On the fig. 2 the effect of the additive on the opacity of exhaust gases is presented. Introduction of the additive to the diesel fuel increases considerably the cetane number (fig. 3), improves the lubricating and low-temperature properties of fuel. 
Operation testing of the influence of the multifunctional additive on the gasoline specific consumption was carried on vehicles which had travelled $20000 \mathrm{~km}$ before the test. The test results are shown in fig. 4. Vehicles with gasoline engines had the octane number of fuel used decreased by 6-10 points after the additive usage.
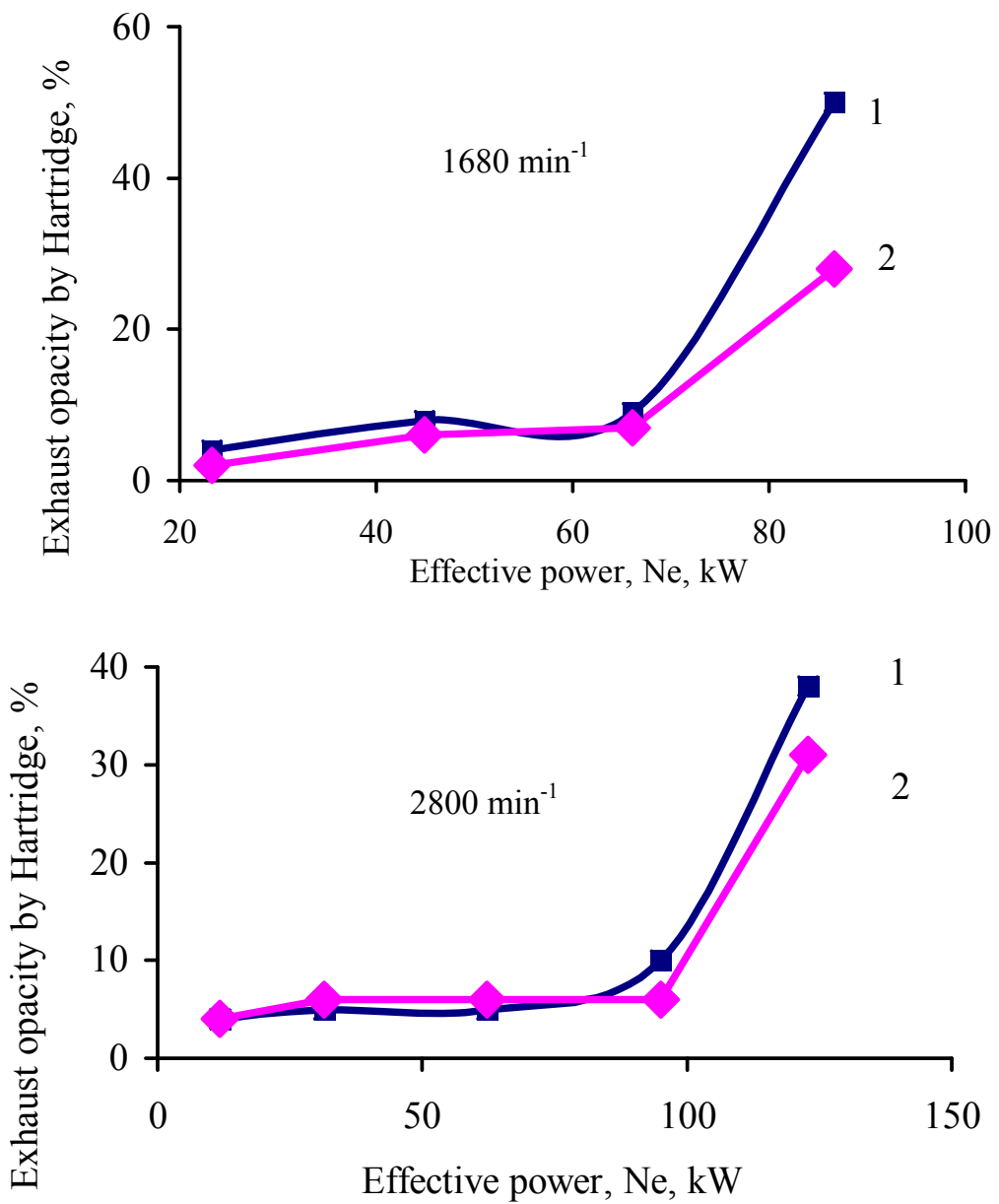

Figure 2: Influence of the additive on the soot emissions. (1- without the additive; 2 - with the additive.) 


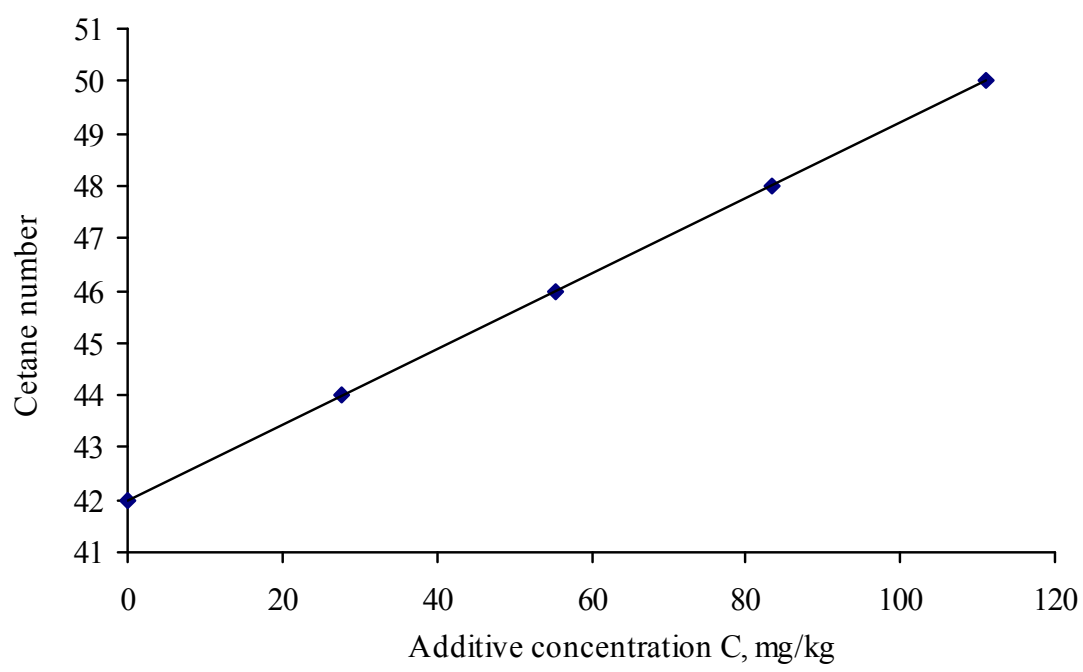

Figure 3: Dependence of cetane number on additive concentration.
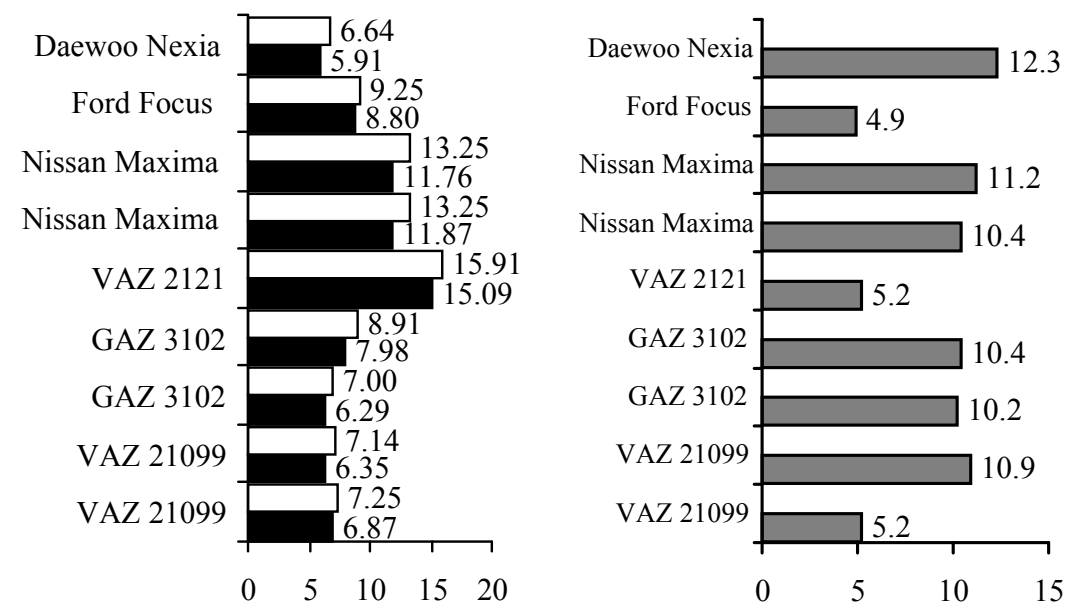

specific gasoline consumption, $1 / 100 \mathrm{~km} \quad$ specific consumption reduction, $\%$

Figure 4: Influence of the additive on the specific consumption of gasoline. ( $\square-$ without the additive; $\mathbf{\square}$ - with the additive.) 
Technical checkout of the engines after the operation testing showed significant purification of spark plugs, valves and cylinder-piston group of the testing vehicles from carbon deposits. In fig. 5 pictures of the Nexia SOHC engines of UZ-Daewoo's vehicles after applying of the additive are presented.

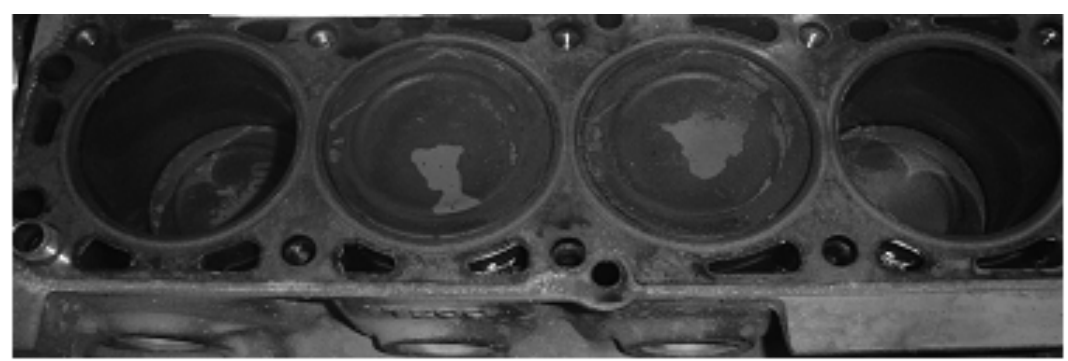

a)

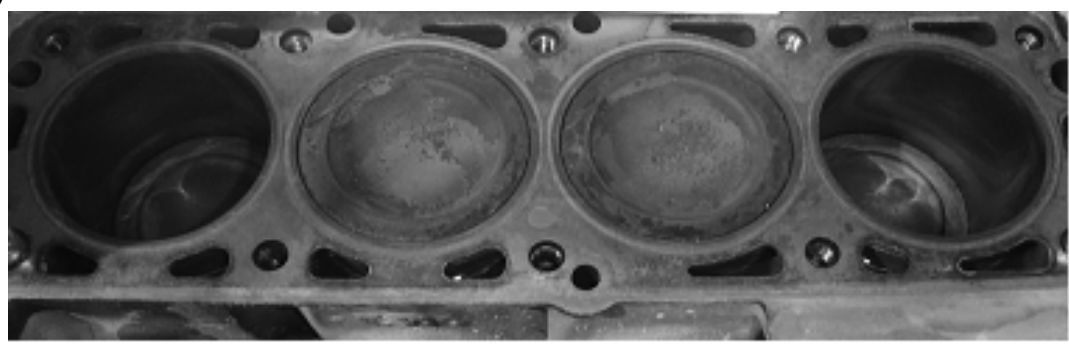

b)

Figure 5: The outward of cylinder-piston group of Nexia SOHC engines of UZ-Daewoo's vehicles after the testing run of $1935 \mathrm{~km}$, a) controlling vehicle and b) testing vehicle after the run with the application of the additive.

The influence of the additive on the emissions of benzo(a)pyrene by vehicles with gasoline engines idling was investigated. It was found that the reduction of the emission of polycyclic aromatic hydrocarbons was $~ 95 \%$ (table 1), which increases durability of the exhaust catalytic converters as well as has an

Table 1: The influence of the additive on the emissions of benzo(a)pyrene and other multiring aromatic hydrocarbon. Vehicle GAZ - 3102, idling.

\begin{tabular}{|c|c|c|}
\hline \multirow{2}{*}{ Gasoline } & \multicolumn{2}{|c|}{ Content in burnt gases, $\mathrm{mg} / \mathrm{m}^{3}$} \\
\cline { 2 - 3 } & benzo(a)pyrene & $\begin{array}{c}\text { Scope of multiring aromatic } \\
\text { hydrocarbon lighter then benzo(a)pyrene }\end{array}$ \\
\hline $\begin{array}{c}\text { Without } \\
\text { additive }\end{array}$ & 0.00023 & 0.00583 \\
\hline With additive & 0.00001 & 0.00030 \\
\hline Change, \% & -95.7 & -94.9 \\
\hline
\end{tabular}


enormous environmental concern. Bench tests of vehicles with gasoline engines has shown that the application of the additive reduces carbon oxide emissions by $15-30 \%$, oxides of nitrogen - up to $26 \%$, hydrocarbons by $8-35 \%$. Cleaning the fuel system from tar deposits takes place as a result of the detergent effect of the additive. The additive has extremely high detergent properties, more efficient than ones of the best detergents (Paradine-50, MPA-85), available on the world market. With the introduction of the additive detergent properties of fuel increase in 2.33 times at a rate almost 20 times smaller than for commonly used additives.

As the surfactant, the additive concentrates on the surface of gasoline decreasing the vapor pressure of gasoline and, as a result the loss from evaporation (fig. 6). The combination of the influence of additives on the vapor pressure and surface tension provides a valuable technical effect, the reduction of the vaporization loss of gasoline, and at the same time, the improvement of the fuel-air mixture formation.

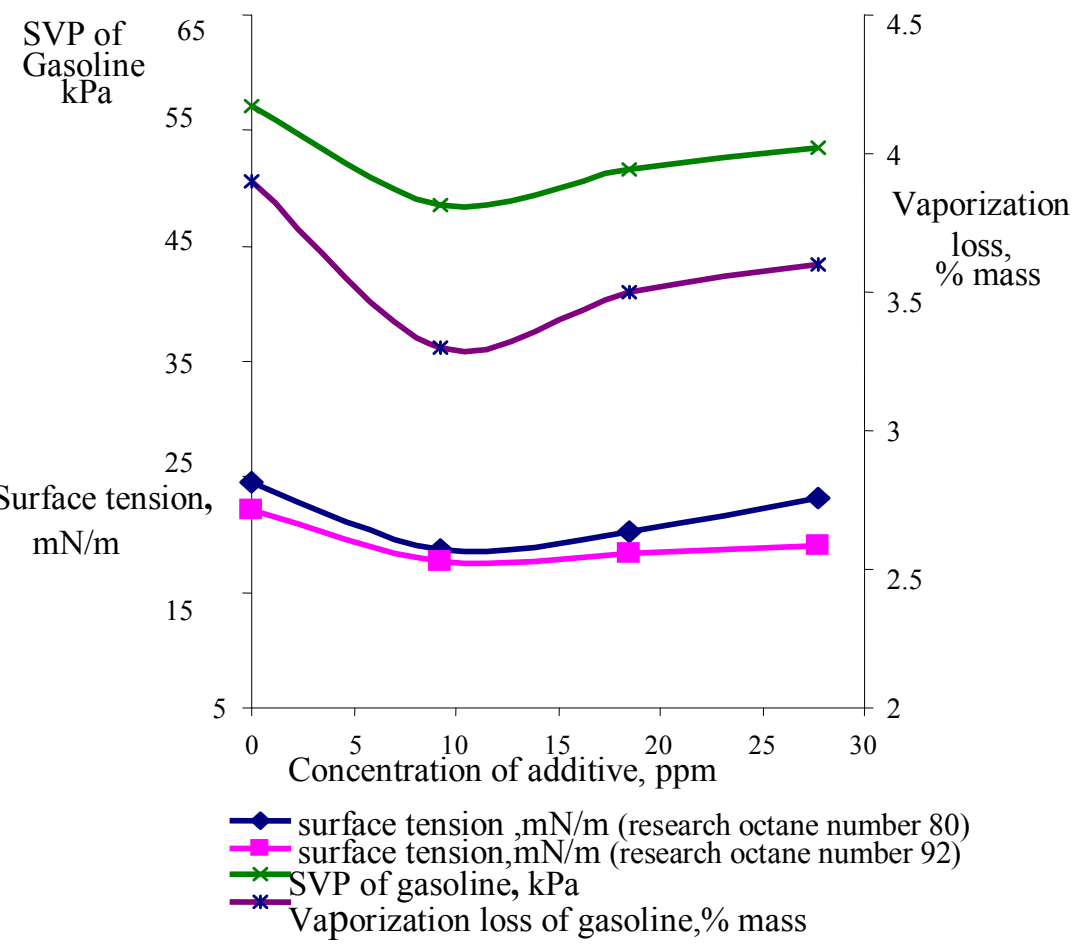

Figure 6: The influence of the additive on the value of surface tension at the $15^{\circ}$, on the SVP of gasoline and the vaporization loss of gasoline.

The atomic-absorption analysis of content showed no additional toxic components in exhaust gases, not observed before the application of the additive. The high efficiency of the developed additive was confirmed by the experimental-industrial application. The additive was used in the production of 
about 360 thousands tons of gasoline and 40 thousands tons of diesel fuel. The additive is synthesized from available, inexpensive components and its production does not require highly qualified specialists and sophisticated equipment. The additive can be introduced into the fuel at all stages: during the production, in a finished fuel, at the petrol stations and directly into the fuel tanks of vehicles. Known and applied monofunctional additives are much less efficient than that proposed, at a consumption rate of 20 - 100 times higher and considerably more expensive. Table 2 compares the efficiency of the developed multifunctional additive and available on the world market additives.

Table 2: Influence of the developed multifunctional additive on the operational and environmental characteristics of vehicles and on the properties of motor fuels (concentration of the additive $9.25 \mathrm{ppm}$ in gasoline and $27.75 \mathrm{ppm}$ in diesel fuel).

\begin{tabular}{|c|c|c|c|}
\hline Characteristics & $\begin{array}{l}\text { Gasoline } \\
\text { engines, } \\
\text { gasoline }\end{array}$ & $\begin{array}{c}\text { Diesel } \\
\text { engines, } \\
\text { diesel fuel }\end{array}$ & Analogs \\
\hline Fuel consumption & $-5-12 \%$ & $-4-7 \%$ & $\begin{array}{l}\text { In agreement with patent } \\
\text { data less efficient by the } \\
\text { rate } 0.1-0.5 \%\end{array}$ \\
\hline $\begin{array}{l}\text { Reduction of carbon } \\
\text { deposits }\end{array}$ & $\sim-95-100 \%$ & $\sim-95-100 \%$ & $\begin{array}{c}\text { less efficient by the rate } \\
0.05-0.10 \%\end{array}$ \\
\hline \begin{tabular}{|c|}
$\begin{array}{c}\text { Detergent properties, } \\
\text { decrease of cleaning } \\
\text { time, times }\end{array}$ \\
\end{tabular} & 2.33 & 2.33 & $\begin{array}{l}\text { The same efficiency by } \\
\text { the rate } 0.025-0.05 \%\end{array}$ \\
\hline \begin{tabular}{|} 
Reduction of emission \\
$\mathrm{CO}$ \\
$\mathrm{NO}_{\mathrm{x}}$ \\
$\mathrm{CH}$ \\
benzo(a)pyrene and \\
its analogs \\
soot
\end{tabular} & $\begin{array}{l}-15-30 \% \\
-20-26 \% \\
-8-35 \% \\
-95-96 \% \\
- \\
\end{array}$ & $\begin{array}{c}-15-17 \% \\
-20-22 \% \\
-35-37 \% \\
- \\
-40-50 \% \\
\end{array}$ & $\begin{array}{l}\text { The same effect by the } \\
\text { concentration in 50-100 } \\
\text { times more. Analogs } \\
\text { with influence on } \\
\text { benzo(a)pyrene are } \\
\text { unknown }\end{array}$ \\
\hline $\begin{array}{c}\text { Decrease of } \\
\text { requirements to octane } \\
\text { number of gasoline }\end{array}$ & $6-10$ items & - & $\begin{array}{c}\text { The same efficiency by } \\
\text { the rate } 50-100 \text { times } \\
\text { more }\end{array}$ \\
\hline Cetane number & - & +3 items & $\begin{array}{c}\text { The same efficiency by } \\
\text { the rate } 18-36 \text { times } \\
\text { more }\end{array}$ \\
\hline $\begin{array}{l}\text { Lubricating properties } \\
\text { (coefficient of static } \\
\text { friction) }\end{array}$ & - & $-25 \%$ & $\begin{array}{l}\text { The same efficiency by } \\
\text { the rate } 0.05-0.10 \%\end{array}$ \\
\hline $\begin{array}{c}\text { Vaporization loss of } \\
\text { gasoline }\end{array}$ & $-15-20 \%$ & - & There are no analogs. \\
\hline
\end{tabular}




\section{Conclusion}

Application of the developed multifunctional additive will quickly improve the environment in big cities and solve in some countries the problem of a shortage of high octane gasoline, with significant savings in fuel consumption without any capital investment in the automobile industry and oil refining.

\section{References}

[1] Magaril, E.R. Influence of the quality of engine fuels on the operation and environmental characteristics of vehicles: monograph [in Russian]. KDU: Moscow, 2008.

[2] Magaril, E.R., Magaril R.Z. Motor fuels [in Russian]. Second edition. KDU: Moscow, 2010. 